\title{
Sinyalize Bir Kavşakta Oluşan Trafik Akımının Kuyruk Teorisi ile Performansının İncelenmesi
}

\author{
Fatih Güneş ${ }^{11}$, Selim Bayraklı², Abdul Halim Zaim ${ }^{3}$ \\ 1 İstanbul Ticaret Üniversitesi, Fen Bilimleri Enstitüsü, Bilgisayar Mühendisliği Bölümü, İstanbul, Türkiye (ORCID: 0000-0002-4111-195X) \\ 2 Milli Savunma Üniversitesi, Hava Harp Okulu, Bilgisayar Mühendisliği Bölümü, İstanbul, Türkiye (ORCID: 0000-0003-3115-6721) \\ 3 İstanbul Ticaret Üniversitesi, Mühendislik Fakültesi, Bilgisayar Mühendisliği Bölümü, İstanbul, Türkiye (ORCID: 0000-0002-0233-064X)
}

(İlk Geliş Tarihi 31 Mart 2020 ve Kabul Tarihi 23 Mayıs 2020)

(DOI: 10.31590/ejosat.711094)

ATIF/REFERENCE: Güneş, F., Bayrakl, S. \& Zaim, A. H. (2020). Sinyalize Bir Kavşakta Oluşan Trafik Akımının Kuyruk Teorisi ile Performansının İncelenmesi. Avrupa Bilim ve Teknoloji Dergisi, (19), 56-65.

Öz

Yapılan bu araştırmada özellikle şehir merkezlerinde trafik yoğunluğunu azaltma amaçlı konumlandırılan sinyalize kavşakların, çalışma prensipleri ve araç akışını düzenleyici yaklaşımları ele alınmıştır. Araç gecikmeleri, sinyal sürelerinin hesaplama yöntemleri ve performans ölçütlerinin çıkarılması ile ilgili analitik yaklaşımlar incelenmiştir. İstanbul Güngören'de seçilen bir kavşaktan loop algılayıcılar ile elde edilen gerçek veriler kullanılarak performansının ortaya çıkarılması amaçlanmıştır. Seçilen bu kavşaktan elde edilen veriler ile yapılan çalışmada iki haftalık veri üzerinden günün en sık araç akışının olduğu üç zaman dilimi incelenmiştir. Kuyruk teorisi, bekleme hattı problemlerinde sıklıkla başvurulan yöntemlerin başında gelmektedir. Kuyruk teorisi modelleri, kendi içinde sisteme gelen bireylerin veya bizim uygulamamızda araçların, geliş, ayrılış ve servis disiplini gibi karakteristiklerine göre farklı notasyon ve hesaplama yöntemlerine sahip olabilmektedir. Kuyruk modellerinin ihtiyaç duyduğu dağılımlar için genellikle varsayımlar yapılmakta ve trafik mühendisliği araştırmalarında gelen akımın rastgele olduğu varsayılmaktadır. Araştırmada araçların gelişleri poisson, gelişler arası sürenin ise üstel dağılıma uyduğu kabul edilmiş̧ir. Pilot olarak seçilen bu kavşaktaki veriler $\mathrm{M} / \mathrm{M} / 1$ kuyruk modeli ile incelenmiş ve sinyalize bir kavşaktaki bağlı kolların kuyruk uzunlukları, sistemde geçirilen zaman, araç başı servis süreleri, ortalama bekleme süreleri gibi ölçütler ortaya çıkarılmıştır. Uygulanan senaryoda kavşak bağlantı kollarının her biri bir kuyruk olarak değerlendirilmiş ve hesaplamalarda her kolun performansı ayrı değerlendirilmiştir. Ortaya çıkan sonuçlara göre günün belli saat dilimlerinde sinyalize sistemlerin optimize çalıșmadığı ve kuyruk uzunluklarını azaltmada yeterli olmadığı sonucuna ulaşılmıștır. Günün bu saat dilimlerinde kavşak kollarına tanınan yeșil sürelerin veya kolların çalışma sıralarının iyileştirmeye ihtiyaç duyduğu söylenebilir. Elde edilen kuyruk uzunlukları veya ortalama bir aracın sistemde kaybettiği zaman dikkate alınarak kavşak modellemesi veya süre dağılımları gözden geçirilmelidir.

Anahtar Kelimeler: Sinyalize kavşaklar, Kuyruk Teorisi, Trafik Yoğunluğu, Akıllı ulaştırma sistemleri

\section{Study of Performance Measures of Traffic Flow at Signalized Intersection with Queueing Theory}

\begin{abstract}
In this study, the working principles of the signalized intersections located in the city centers to reduce the traffic density and the approaches to regulate the flow of vehicles are discussed. Analytical approaches related to vehicle delays, calculation methods of signal times and performance criteria were investigated. In the study made with the data obtained from this selected intersection, three time
\end{abstract}

\footnotetext{
${ }^{1}$ Sorumlu Yazar: İstanbul Ticaret Üniversitesi, Fen Bilimleri Enstitüsü, Bilgisayar Mühendisliği Bölümü, İstanbul, Türkiye, ORCID: 0000-0002-4111195X, fgunes41@gmail.com
} 
periods with the most frequent vehicle flow of the day were examined over two weeks of data. Queue theory is one of the most frequently used methods in waiting line problems. Queue theory models can have different notation and calculation methods according to the characteristics of individuals coming to the system or vehicles in our application such as arrival, departure, and service discipline. Generally, assumptions are made for the distributions required by queuing models and the current arrivals in traffic engineering research are assumed to be random. It is aimed to reveal its performance by using real data obtained with loop sensors from an intersection in Güngören, Istanbul. The data at this intersection chosen as a pilot was analyzed with the M/M/1 queue model and criteria such as the queue lengths of the connected arms at a signalized intersection, the time spent in the system, the service time per vehicle, and the average waiting times were revealed. In the applied scenario, each of the junction link arms was evaluated as a queue and the performance of each arm was evaluated separately in the calculations. According to the results, it is concluded that the signaled systems do not work optimized in certain time zones of the day and are not sufficient in decreasing the tail lengths. In these time zones of the day, it can be said that the green times given to the junction arms or the working order of the arms need improvement.

Keywords: Signalized Intersections, Queuing Theory, Analysis of Traffic Density, Intelligent Transportation Systems

\section{Giriş}

Şehir merkezlerinde artan nüfus yoğunluğu beraberinde birçok problemin ortaya çıkmasına sebep olmaktadır. Bu yoğunluk sebebiyle araç kullanıcıları veya toplu taşıma araçları, zaman, yakıt, enerji gibi birçok konuda kayıplar yaşamaktadır. Bu alanda gerek literatürde akademik olarak gerekse de akıllı ulaştırma sistemleri üreten firmalar tarafından birçok çalışma yapılmıştır ve yapılmaya da devam edilmektedir (Cakici, Murat ve Aydın, 2019). Yapılan, bütün çalışmalar bu alandaki yenilikçi yaklaşımların temelini oluşturmuştur. Gelişmekte olan haberleşme sistemleri, kablosuz ağ teknolojileri ve sensör teknolojileri de bu çalışmalara hız kazandırmıştır. Genel olarak yeni nesil algılayıcılar veya kamera sistemleri ile toplanan araç sayısı, cinsi, yoğunluğu gibi parametreler kullanılarak ulaşımda kullanılan sistemlerin iyileştirmesi veya optimizasyonu üzerinde çalışılmaktadır (Zhou, Cao, Zeng ve Wu, 2010). Hatta konu ile ilgili yapılan son çalışmalarda makine öğrenmesi teknikleri ile artık tahminleme, sınıflandırma gibi analizlerin de öne çıktığını görmekteyiz (Yisheng, Duan, Kang, Li ve Wang 2015). Enerji tüketiminden toplu yaşama ulaştırmadan sağlığa kadar birçok alanda bu sorunlar şehir yöneticileri tarafından tartışılmaktadır. Akıllı şehir teknolojileri alanında yapılan araştırma ve geliştirmelerin tamamı bu sorunların çözümüne odaklanmaktadır. Gelişen teknolojiler ile ulaşım anlamında karayollarında sensörlerden, kamera algılayıcılara kadar birçok gelişme uzaktan kontrollü trafik sistemlerinin yaygınlaşmasına katkı sağlamaktadır (Armağan, 2019). Bu bağlamda toplu yaşamı etkileyen çalışmaların başında ulaştırma ve trafik sorunu gelmektedir. Ulaştırma alanındaki araştırmalar, insanların ve taşıtların günlük yaşamdaki akışını optimize etmeyi ve rahatlatmayı amaçlar. Sürekli artan araç ve yolcu sayısı ve mevcut altyapılar tarafından sağlanan kaynakların sınırlı olması, trafiğin akıllıca kontrolünün önemini her geçen gün artırmaktadır. Trafik sıkışıklığının ve yoğunluğunun azaltılmasının çevresel ve ekonomik olarak birçok faydası bulunmaktadır.

Şehir içi trafiği düzenleyici kontrollerin başında sinyalize kavşaklar ve trafik 1şıkları gelmektedir. Şehir içi trafiğindeki taşıtlar, yetersiz trafik 1şı ğı kontrolü nedeniyle uzun seyahat süreleri yaşayabilmektedirler. Yaşanabilecek bu yoğunluklar birden fazla kavşağı veya geçiş güzergahını etkileyebilir. Trafik ışıklarının gelişmiş sensörler ve akıllı optimizasyon algoritmaları kullanılarak optimum kontrolü bu nedenle çok faydalı olabilir. Trafik ışı̆̆ı sürelerinin optimizasyonu, yol kapasitesini ve trafik akışını artırır ve trafik sıkışıklığını önleyebilir (Çakıcı ve Murat, 2015). Trafik 1şı̆̆ı kontrolü ve optimizasyon problemlerinde şimdiye kadar birçok farklı yaklaşım ele alınmıştır. Bu kapsamda yapılan çalışmaların gecikme problemleri, süre optimizasyonu, kuyruklanma, tahminleme gibi sorunlar üzerinde yoğunlaştıği görülmektedir.

Yapılan bu araştırmada şehir merkezlerinde oluşan trafik yoğunluğu özelinde yapılan analitik yaklaşımlar ele alınmıştır. Özellikle trafiğin en önemli düzenleyicisi olarak kullanılmakta olan sinyalize kavşaklardaki gecikme ve performans ölçümlerine temel teşkil eden yöntemler incelenmiştir. Çalışmanın ilk kısmında sinyalize kavşakların çalışma prensiplerinin anlatılmasının ardından literatürde öne çıkan yöntemler ve son olarak da sinyalize kavşak kollarının performansı kuyruk teorisi ile incelenerek bir dizi sonuçlar elde edilmiştir. Sistem ve kuyruk performansı adına önemli birer parametre olarak değerlendirilebilecek kuyruk uzunlukları, ortalama araç beklemeleri, sistemde geçirilen zaman, yoğunluk oranları gibi değerler elde edilmiştir.

\section{Materyal ve Metod}

\subsection{Sinyalizasyon Sistemleri ve Kavşaklar}

Trafik 1şıkları veya sinyalizasyon sistemleri kavşaklarda daha güvenli performans elde edilmesinde önemli bir rol oynamaktadır. Araştırmalar, trafik sinyallerinin düzgün bir şekilde kurulması ve çalıştırılmasının trafik kazalarını azaltabileceğini göstermektedir. (Özen, 2020). Bununla birlikte, gereksiz veya uygun olmayan bir şekilde tasarlanmış sinyal süreleri trafik, güvenlik ve mobiliteyi olumsuz yönde etkilemektedir. Yerleşimlerine, tasarımlarına ve zamanlamasına çok dikkat edilmesi gerekir. Bazı durumlarda, çok iyi optimizasyon, araç talebini artırabileceğinden aynı güzergahtaki farklı noktalarda yoğunlukların oluşmasına da sebebiyet verebilir (Calışkanelli, 2010). Bu yüzden çoğu senaryolarda öncelik olarak güvenliğin sağlanması amaçlandığından artan ve değişen talepleri karşılamak için, bir durumdan diğer bir durumdaki iyileşmeyi sağlaması adına vazgeçilmesi veya tekrar değerlendirilmesi gerekebilir (Ilıcalı vd., 2016). Trafik sinyallerinin çalışma yöntemlerinin olası bütün koşullar için incelenmesi oldukça önemlidir. Herhangi bir kavşakta ya da bir akış güzergahında aşağıdaki koşullardan herhangi birisinin oluşması durumunda trafik sinyalize sistemin gerekliliği ortaya çıkmaktadır (Ayfer, 1977); 
- Seyahat gecikmesinin optimizasyonu.

- Kaza sıklı̆ğının ve / veya şiddetinin azaltılması.

- Belirli yol kullanıcı tipi veya hareketine (yayalar veya sola dönüş hareketleri gibi) öncelik verilmesi.

- Yeni bir kavşak yaklaşımı veya trafik hacminde artış (yeni bir gelişime bir yaklaşım eklemek gibi).

Trafik sinyalizayonunun kurulumu, trafik hacmi verileri, çarpışma geçmişi, yol geometrisi ve alan koşullarının analiz edilmesiyle belirlenmektedir. Planlamacılar, tasarımcılar ve trafik mühendisleri, koşulların kurulum için uygun olup olmadığını belirlemek için birlikte çalışır. Bu koşullar her yeni trafik ışığı kurulumunda yaya ve taşıt güvenliği için göz önünde bulundurulmaktadır.

Sinyalize kavşaklardaki trafik ışıkları yol durumuna, taşıt yoğunluğuna veya bağlantı kollarına göre birden fazla çalışma prensibine sahip olabilir. Sinyal çalışma prensipleri önceden zamanlanmış sabit süreli, yarı adaptiv süreli, tam adaptiv, hibrit veya trafiğe duyarlı olarak farklı operasyon şekillerine ayrılmaktadır (Harb, Durdu ve Terzioğlu, 2019)

\subsubsection{Sinyalize Kavşaklarda performans kriterleri}

Sinyalize kavşaklar, karayolları ve şehir içi ulaşım sistemindeki önemli noktalar veya düğümlerdir. Sinyalize bir kavşağı değerlendirmek ya da operasyon kalitesini tanımlamak için belirli bir yöntem önermek oldukça zor bir iştir. Kapasite analizi veya hizmet süresi gibi ölçümler kullanılarak kavşakların yeterlilikleri simülasyon araçları yardımıyla değerlendirilebilmektedir. Burada genelde karakteristik olarak kullanılan en yaygın kriterlerin başında araç başına ortalama gecikme, ortalama kuyruk uzunluğu ve duraksama sayıları gelmektedir. Gecikme, sürücünün deneyimini doğrudan ilişkilendiren ve kavşaktan geçmek için harcanan fazla zamanın ölçüsüdür (Bullock, 2008). Herhangi bir zamandaki kuyruk uzunluğu bilgisi ise, belirli bir kavşağın belli bir kolunda oluşabilecek birikmenin ne zaman boşaltılması gerektiğini belirlemede kritik bir öneme sahiptir. Kavşak hizmet kalitesinin ölçülmesinde kullanılan diğer önemli ölçülerden duraksama sayısı ise çevresel veya hava kalitesi değerlendirme modelleri için değerli bir giriş parametresidir.

\subsection{Trafik problemlerinde analitik yaklaşımlar ve gecikme modelleri}

Literatürde trafik problemi üzerine yapılan çalışmaların ağırlıklı olarak araç, sistem gecikmeleri ve kuyruklanma problemleri üzerinde yoğunlaştığı söylenebilir. Gecikme ve kuyruklanma parametreleri kavşak kapasitesi ve hizmet seviyesinin yeterliliğinin sorgulanmasında ve yakıt emisyonu problemlerinin değerlendirilmesinde kullanılan en temel performans ölçütlerindendir. Trafik mühendislerinin ve çevre otoritelerinin üzerinde durduğu en önemli hedef maksimum hizmet seviyesi ve minimum gecikmedir. Gecikme verisi ile ayrıca bir kavşak noktasının farklı kontrol, talep ve çalışma koşullarının performansı da karşılaştırılabilir. Bu nedenle, gecikmenin doğru tahmini çok önemlidir, ancak rastgele trafik akışları ve diğer kontrol edilemeyen faktörler nedeniyle doğru tahmin zor bir problemdir. Gecikme, saha ölçümleri kullanılarak simülasyon ve analitik modellerle tahmin edilebilir. Bu yöntemlerden, analitik tahmin en pratik ve kullanışlıdır. Sinyalize kavşaklarda gecikmenin tahmin edilmesinde, çeşitli trafik koşulları için farklı varsayımlar kullanılarak bir takım analitik modeller önerilmiş ve geliştirilmiştir (Dion, Rakha ve Kang, 2004).

Gecikme tahmininde önerilen stokastik modeller genelde kararlı durum yani kavşağa gelen araçların geliş oranlarının kavşağın hizmet seviyesi oranlarından düşük olduğu durumlar için geçerlidir. Fakat bu modellerin kavşak kapasitesinin doygunluğa ulaşmış durumları için uygulanması pek mümkün değil. Deterministik modeller ise, aşırı doygun koşullar için gecikmeyi tahmin etmek için daha gerçekçi olmasına karşın trafik akışındaki rasgeleliğin etkisini görmezden gelmektedir. Hem stokastik kararlı durumdaki hem de deterministik gecikme modellerindeki eksikliklerin üstesinden gelmek için zamana bağlı gecikme modelleri geliştirilmiş̧ir. Bu modeller, stokastik kararlı durumu ve deterministik modelleri, koordinat dönüşüm tekniğini kullanarak birleştirerek daha gerçekçi gecikme modelleri sağlamaktadır (Ağırdır, 1998).

Sinyalize bir kavşaktaki gecikme bir aracın trafik ışı̆̆ı kontrolünde geçerken yaşamış olduğu zaman kaybı ile trafik sinyalinin yokluğunda geçirmiş olduğu zaman kaybının farkı olarak tanımlanmaktadır. Şekil 1'de ayrıca bir aracın yaşadığı toplam gecikmenin yavaşlama gecikmesine, durma gecikmesine ve hızlanma gecikmesine göre ayrılabileceğini görülmektedir Ulaştırma ve trafik mühendisleri durma gecikmesini, aracın tamamen hareketsiz durumda geçirdiği zaman ile kavşağa yaklaşma ve kalkış anındaki zamanın toplamı olarak açıklamaktadırlar. Bazı durumlarda durma anındaki gecikmeye aşırı yavaş hızda hareket eden aracın hızı da dahil edilmektedir. 


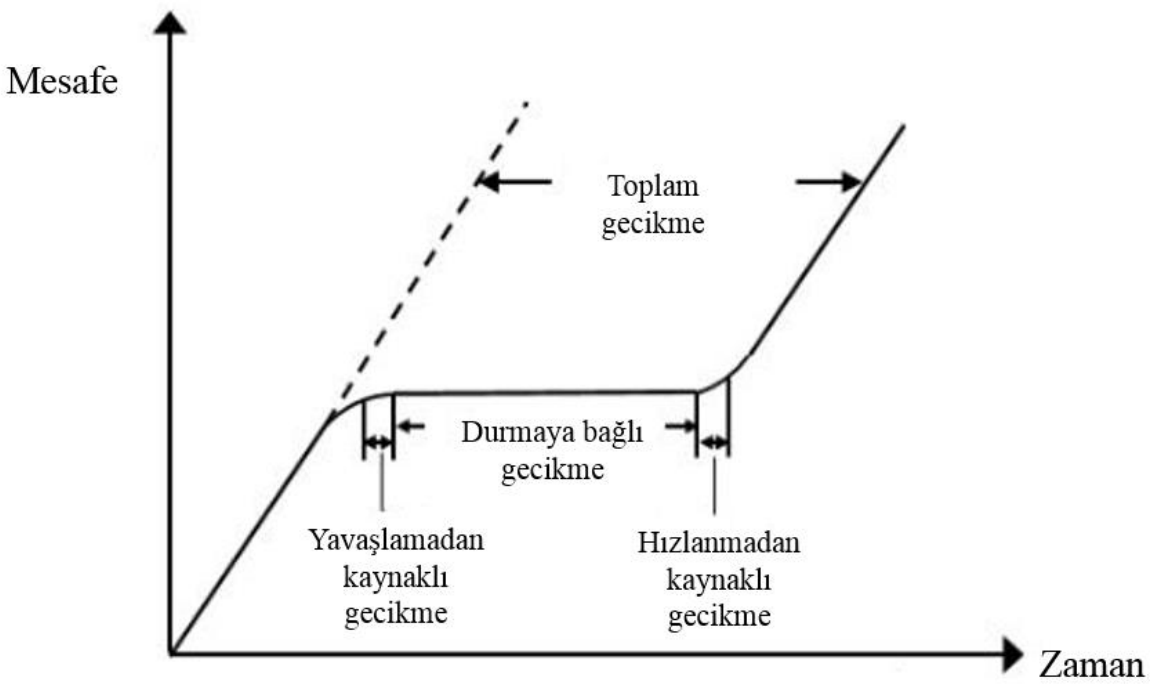

Şekil 1 - Taşıt gecikme diyagramı (Murat ve Cakici, 2017)

Sinyalize kavşaklarda gecikme hesabı için geliştirilen ilk çalışmalar Avustralya (Akcelik), İngiliz (Webster) ve H.C.M. (Highway Capacity Manual) yöntemleridir. (Akgungor, 1999).

\subsubsection{Webster Modeli}

1958'de Webster (webster, 1958) tarafından geliştirilen bu gecikme modeli, sinyalize kavşaklardaki taşıtların gecikmesini inceleyen ilk araştırmalardandır. 1958 'de geliştirilen ve İngiliz yöntemi olarak da bilinen Webster denklemi, varış sürelerinin Poisson, servis sürelerinin ise sabit olduğunu varsayarak M/D/1 kuyruk sistemini kullanan ilk gecikme denklemlerinden biridir (Webster, 1958). Ancak servis sürelerinin de rastgele olduğu durumlarda, modelin gerçekçi olmayacağını ileri süren birçok araştırmacı bu modelden yola çıkarak geliştirmelere devam etmişlerdir. Ayrıca, trafik talebi doygunluğa yaklaştıkça tahmini gecikmeler de sonsuza eğilimlidir. Webster modeli ve tanımları şu şekildedir;

$$
d=\frac{C(1-\lambda)^{2}}{2(1-\lambda x)}+\frac{x^{2}}{2 q(1-x)}-0,65\left(\frac{C}{q^{2}}\right)^{1 / 3} x^{(2+5 x)}
$$

Tanımdaki ifadeler ise;

$$
\begin{aligned}
& \lambda=\text { yeşil oranı }, \\
& x=\text { doygunluk oranı } \\
& q=\text { kavşak kollarındaki akış oranı } \\
& c=\text { Devre Süresi } \\
& d=\text { Taşıt başı ortalama gecikme }
\end{aligned}
$$

Webster modelindeki ilk terim araçların uniform geliş ve gidiş oranları ile yaşadığı gecikmeyi ifade ederken ikinci terim ise rastgele gelişe sahip taşıtların etkisini açılamaktadır. Webster modelindeki son kısım ise toplam gecikmenin $\% 5 \mathrm{ile} \% 15$ 'ini ifade eden düzeltme terimidir. Formulasyonu basitleştirmek amacıyla genelde son terim kullanılmamaktadır, modeldeki ilk iki terimin toplamı 0,9 gibi bir oranla çarpılarak daha kısa bir biçimde ifade edilmektedir (Webster, 1958).

Genel ifade en basit haliyle aşağıdaki gibidir;

$$
d=\frac{9}{10}\left(\frac{C(1-\lambda)^{2}}{2(1-\lambda x)}+\frac{x^{2}}{2 q(1-x)}\right)
$$

\subsubsection{Akçelik Gecikme Modeli}

Avustralya yöntemi olarak da bilinen Akçelik gecikme modelinde ise kavşak kollarında veya herhangi bir yaklaşım yolu üzerindeki birikme veya kuyruklanma referans alınarak farklı bir gecikme modeli önerilmiştir. Önerilen bu model ilk olarak Avustralya Karayolları araştırma birimi kavşaklarında uygulanmıştır. Bu modelde öncelikle araç sayısı, akım oranı, yeşil süresi gibi parametreler dikkate alınarak kuyruk uzunluğu elde edilmektedir. Önerilen model (Akcelik, 1988) ise şu şekildedir; 


$$
\begin{gathered}
O D=\left\{\left(\frac{T}{4}\right)\left\{(x-1)+\left[(x-1)^{2}+12\left(x-x_{0}\right) / c T\right]^{1 / 2}\right\} \text { ĕ } \text { er } x>x_{0}\right. \\
0 \text { diğer durumlarda } \\
x=\frac{v}{c} \text { ve } x_{0}=0.67+\mathrm{sg} / 600
\end{gathered}
$$

Tanımdaki ifadeler ise;

$$
\begin{aligned}
& O D=\text { ortalama kuyruk uzunluğu (araç sayısı cinsinden), } \\
& T=\text { Periyod } \\
& s=\text { doygun akım oranı (araç/saniye) } \\
& c=\text { kapasite (araç/saat) } \\
& g=\text { etkin yeşil süre } \\
& v=\text { akım oranı } \\
& x_{0}=\text { doygunluk derecesi }
\end{aligned}
$$

Gecikme için önerilen model ise;

$$
W=\frac{q * D *(1-u)^{2}}{2 *(1-y)}+O D * x
$$

Tanımdaki ifadeler ise;

$$
\begin{aligned}
& O D=\text { ortalama kuyruk uzunluğu (araç sayısı cinsinden), } \\
& W=\text { Gecikme } \\
& O D=\text { ortalama kuyruk uzunluğu (araç sayısı cinsinden), } \\
& \mathrm{D}=\text { Devre süresi } \\
& \mathrm{q}=\text { Akım (taşıt/sn) } \\
& \mathrm{s} \quad=\text { doygun akım oranı (araç/saniye) } \\
& g \quad=\text { etkin yeşil süre } \\
& \mathrm{u} \quad=\mathrm{g} / \mathrm{D} \\
& \mathrm{y} \quad=\mathrm{q} / \mathrm{s}
\end{aligned}
$$

gösterimleri kullanılarak ifade edilmektedir.

\subsubsection{HCM 2000 (Highway Capacity Manual) Gecikme Modeli}

1985 yılında öne sürülen HCM yöntemi sinyalize sistemler ile ilgili kapasite ve gecikme modeli öneren ilk analitik çalışmalardandır. Daha sonraki yıllarda temel bileşenleri değiştirilmeden farklı koşullar da eklenerek HCM 2000 yöntemi olarak en güncel halini almıştır. Bu gecikme modeli temelde iki bileşenden oluşmaktadır:

Birinci terim (d1): Trafik geliş ve gidişlerinin, analiz süresi boyunca hem tek bir sinyal döngüsü hem de tüm döngüler boyunca tamamen aynı (Uniform) olduğunu varsayarak, ortalama döngüde araç başına ortalama gecikmeyi tanımlar.

İkinci terim (d2): Gelişlerdeki rastgelelik nedeniyle her bir döngüde oluşan artımlı gecikmeyi tanımlar. Artımlı gecikme, kararlı durum koşullarını varsayar (HCM, 1985).

1985'te öne sürülen yöntemlere ek olarak HCM'nin daha sonraki güncellemelerinde (HCM, 1994, 1997 ve 2000) çeşitli yapısal değişiklikler yapıldı, ancak yöntemin temel yapısı değişmedi. Bu değişiklikler özetle şunları içeriyordu:

Modelde kullanılan Webster'in orijinal artımlı gecikme terimi, Kimber ve Hollis (Kimber ve Hollis, 1979) tarafindan daha önce geliştirilen zaman bağımlı koordinat dönüşümlü metodu ile değiştirilmiş̧ir. Daha sonra Fambro ve arkadaşlarının çalışmaları (Fambro 
vd., 1996) ile araçların her bir döngüde geliş ve kalkış karakteristiklerinin de modele yansıtılması sağlanmıştır. Model özetle şu şekilde tanımlanmaktadır (HCM, 2000);

$$
\begin{aligned}
& d=d_{1} P F+d_{2}+d_{3} \\
& d_{1}=\frac{1}{2}\left(\frac{c\left(1-\frac{g}{c}\right)^{2}}{\left[\min (1, X)\left(\frac{g}{c}\right)\right]}\right) \\
& d_{2}=900 T\left[(X-1)+\left((x-1)^{2}+\frac{8 k l X}{c T}\right)^{\frac{1}{2}}\right]
\end{aligned}
$$

Tanımdaki ifadeler ise;

$$
\begin{array}{ll}
d_{1} & =\text { uniform gecikme bileşeni } \\
\mathrm{c} & =\text { Devre süresi } \\
\mathrm{g} & =\text { yeşil süre } \\
\mathrm{x} & =\text { doygunluk oranı } \\
d_{2} & =\text { artımlı gecikme bileşeni } \\
\mathrm{T} & =\text { Analiz periyodu } \\
\mathrm{k} & =\text { artımlı gecikme sabiti (sabit zamanlı sistemleri için } 0,5) \\
1 & =\text { ölçüm düzeltme faktörü } \\
\mathrm{c} & =\text { şerit kapasitesi } \\
d_{3} & =\text { önceki devreden kalma kuyruktan dolayı oluşan gecikme bileşeni } \\
\mathrm{PF} & =\text { Sinyal düzeltme faktörü (Progression Factor) }
\end{array}
$$

\subsubsection{Kuyruk Teorisi (M/M/1) Modeli}

Kavşak veya şehir içi trafik akışının ölçülebilmesi veya iyileştirilebilmesinin bir yolu da bir modelleme yoluna başvurmaktır, sadece makul bir eğri üretmeye çalışmak yerine, gerçek kuyruk davranışı modellenmeye çalışllabilir. Kuyruk teorisi bekleme, kuyruklanma, gecikme gibi olayların olduğu birçok problemde başvurulan metodların başında gelmiştir. Trafik problemlerinde ise sinyalize veya sinyalize olmayan birçok kavşak probleminde kullanıldığı görülmektedir. Herhangi bir hizmet verme senaryosunda gelen talebin servis sağlama kapasitesini aştığı durumlarda kuyruklanma meydana gelir. Kuyruk teorisi bu bekleme hatlarının matematiksel modellemesi üzerine yapılan çalışmaları içermektedir. Kuyruk teorisi bu tür bekleme hattı problemlerinde birçok alternatif model ile bekleme süresi, ortalama araç sayısı, kuyruk uzunluğu gibi parametrelerin modellenmesini sağlar (Heidemann, 1974).

Kuyruk modellerinin üç temel bileşeni vardır. Bunlar sırasıyla geliş süreci, hizmet süreci ve kuyruk yapısıdır. Bu çalışmada tek bir kavşağın her bir kolunun ayrı modellenmesi düşünüldüğü için standart bir kuyruk yaklaşımı olan $\mathrm{M} / \mathrm{M} / 1$ modeli kullanılmıştır. Bu modelde gelişler ve ayrılışların dağılımlarının Poisson dağılıma uygun olduğu gelişler arası veya servis sürelerinin üssel olduğu varsayılmaktadır. Denklem 9'da verilen Poisson olasılık yoğunluk denklemi, 0 ile $t$ zamanı periyodunda $n$ aracın gelme olasılığını açıklamaktadır. Negatif üssel dağılım ise trafik akımlarının modellenmesinde en çok başvurulan dağılımlardan birisidir. Bu fonksiyon belli bir olasılığın bir zaman aralığında nasıl dağıldığı, bu çalışmada araçların gelişler arası sürelerinin nasıl dağıldığı hakkında bilgi verir. Denklem 10, 0 ile $t$ arasındaki bir aralıkta hiçbir gelişin gerçekleşmeme olasılı̆̆ının, kuyruk uzunluğu ile negatif üssel orantısıyla ilişkili olduğunu göstermektedir (Buckley, 1962).

$$
\begin{aligned}
& P_{n}(t)=\frac{(\lambda t)^{n}}{n !} e^{-\lambda t} \\
& P_{0}(t)=e^{-\lambda t}
\end{aligned}
$$

Burada verilerin veya servis sürecinin farklılığına göre alternatif kuyruk modelleri önerilebilmektedir. Modelin genel notasyonu (M/M/1):(FIFO/o//o) şeklinde gösterilmektedir. M/M/1 modelindeki 1 sayısı ile servis kanalı yani uygulanan senaryoda tek bir trafik lambasının varlığı tanımlanmaktadır. İlk iki terim geliş ve gidişlerin dağılımlarını, FIFO (ilk giren ilk çıkar) servis yapısını, son iki terim ise sonsuz kaynak ve sistem kapasitesini tanımlamaktadır. 


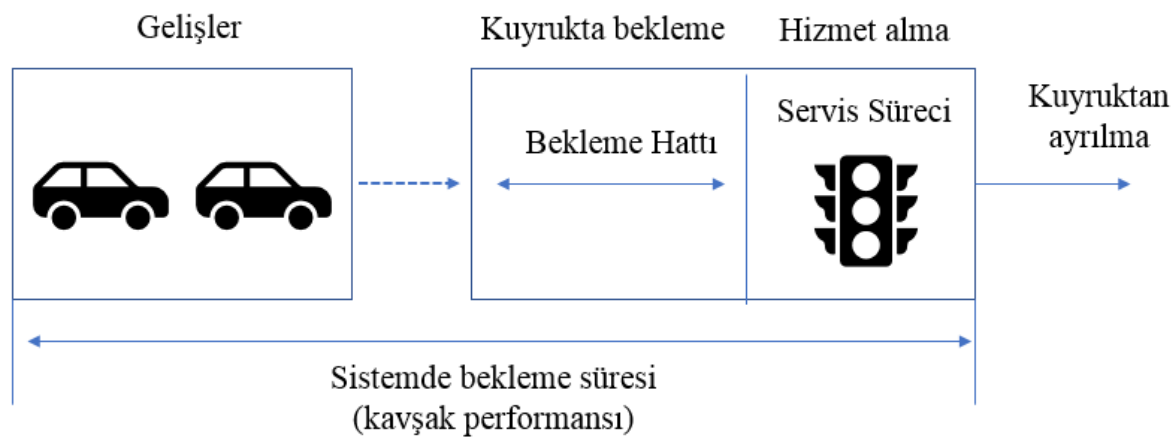

Şekil 2 Kuyruk hattı bileşenleri

$\mathrm{Bu}$ alandaki uygulamalarda kuyruk modellerinin yaklaşım teknikleri ile farklı kuramlar ilişkilendirilmektedir. Kararlı kuyruk sistemlerine uygulanabilen Little Yasası ise, kuyruk yapısının metrikleriyle (varış oranının kalkış oranından daha büyük olmadığı durumlarda) ilişkilendirilmektedir. Bu teori ile, kararlı bir sistemde kuyruk veya sistemdeki araç sayısı ile araç başı bekleme sürelerinin ilişkili olduğu söylenmektedir. Buna iliş̧in modelde kullanılan metrikler ve karşılıkları Tablo 1'de verilmiştir.

Tablo 1 Kuyruk modeli tanımları

\begin{tabular}{|c|c|c|}
\hline Notasyon & Tanımlar & Formülasyonlar \\
\hline$n$ & Sistemdeki maksimum araç sayısı & \\
\hline$P_{n}(t)$ & t anında sistemde $n$ müssteri olma olasillğ & \\
\hline$\lambda$ & $\begin{array}{l}\text { Birim zamanda gelen ortalama araç sayısı } \\
\text { (Geliş oranı) }\end{array}$ & \\
\hline$\mu$ & $\begin{array}{l}\text { Birim zamanda hizmet alan araç sayısı } \\
\text { (Hizmet oranı) }\end{array}$ & \\
\hline$\rho$ & Trafik yoğunluğu & $\rho=\frac{\lambda}{\mu^{\prime}} \rho<1$ \\
\hline$c$ & Servis kanal saylst & \\
\hline$q$ & Servis kullanım oranı & $q=\rho / c$ \\
\hline$w_{s}$ & Sistemde araç başı ortalama bekleme zamanı & $W_{s}=\frac{1}{\mu-\lambda}$ \\
\hline$w_{q}$ & Kuyrukta araç başı ortalama bekleme zamanı & $W_{q}=\frac{\lambda}{\mu(\mu-\lambda)}$ \\
\hline$L_{s}$ & Sistemde beklenen araç sayısı & $L_{s}=\frac{\lambda}{\mu-\lambda}$ \\
\hline$L_{q}$ & Kuyrukta beklenen araç sayısı & $L_{q}=\frac{\lambda^{2}}{\mu(\mu-\lambda)}$ \\
\hline$P\left(W_{s}>t\right)$ & $\begin{array}{l}t \text { aninda sistemde } t \text { den daha fazla zaman } \\
\text { harcama ihtimali }\end{array}$ & $P\left(W_{s}>t\right)=e^{-(\mu-\lambda) t}$ \\
\hline$P\left(W_{q}>t\right)$ & $\begin{array}{l}\text { t aninda kuyrukta t den daha fazla zaman } \\
\text { harcama ihtimali }\end{array}$ & $P\left(W_{q}>t\right)=\rho \cdot e^{-(\mu-\lambda) t}$ \\
\hline
\end{tabular}

\section{Araştırma Sonuçları ve Tartışma}

\subsection{Modelin uygulanması}

Çalışma kapsamında İstanbul ili Güngören ilçesinde Şekil 3’te krokisi verilen kavşak incelenmiştir. Kavşak yaklaşım kollarında ve çıkışlarında bulunan loop ve kamera algılayıcılardan elde edilen sayım verileri İstanbul Büyükşehir Trafik Sinyalizasyon biriminden temin edilmiştir. 


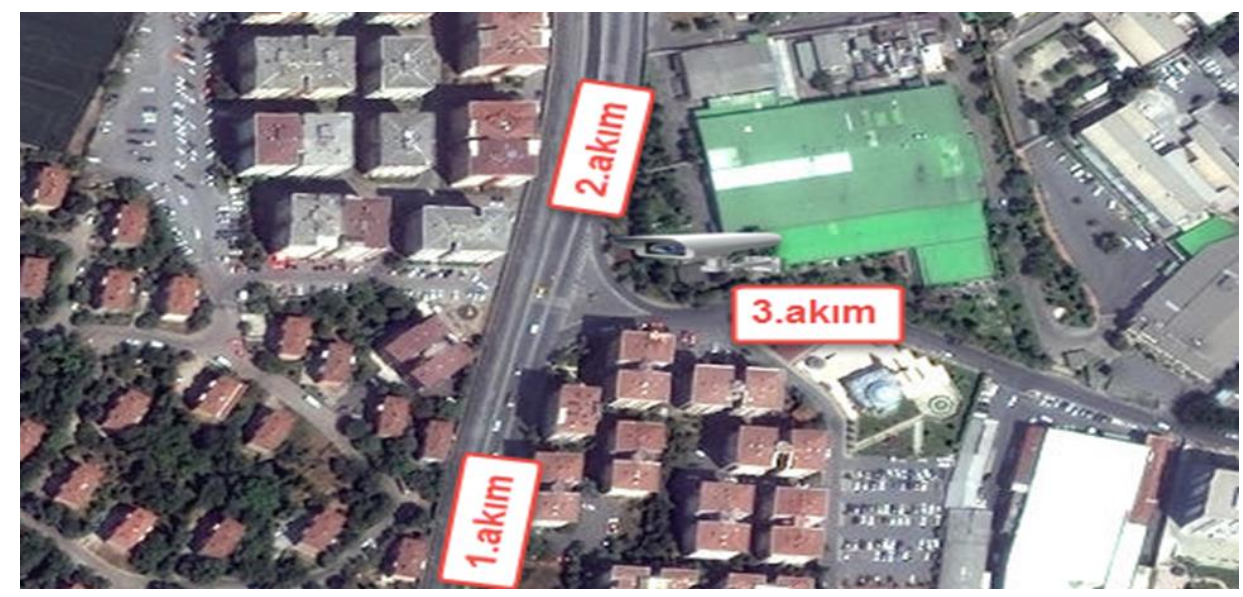

Şekil 3 General Ali Rıza Gürcan Cd üzerindeki kavşak krokisi

Pilot olarak seçilen kavşaktan elde edilen veriler ile yapılan çalışmada iki haftalık veri üzerinden günün en sık araç akışının olduğu üç zaman periyodu incelenmiştir. Sabah 7-10 aralığı, öğle 10-14 aralığı ve akşam 16-20 aralığındaki zaman dilimlerindeki iki haftalık verinin ortalamaları alınarak sistem analiz edilmiştir.

Tablo 2 Günün üç zaman periyodunda kavşak analiz sonuçlart

\begin{tabular}{|c|c|c|c|c|c|c|c|}
\hline Akım & Zaman periyodu & $\begin{array}{l}\text { Geliş } \\
\text { Oranı }\end{array}$ & $\begin{array}{l}\text { Hizmet } \\
\text { Oranı }\end{array}$ & Yoğunluk & $\begin{array}{l}\text { Sistemdeki } \\
\text { araç sayısı }\end{array}$ & $\begin{array}{c}\text { Sistemde } \\
\text { geçirilen } \\
\text { ortalama zaman } \\
\text { (sn) }\end{array}$ & $\begin{array}{c}\text { Kuyrukta geçirilen } \\
\text { ortalama zaman (sn) }\end{array}$ \\
\hline 1. Akım & $07: 00-10: 00$ & 7,23 & 7,32 & 0,99 & 80,33 & 11,11 & 10,97 \\
\hline 2. Akım & $07: 00-10: 00$ & 7,03 & 7,21 & 0,98 & 39,06 & 5,56 & 5,42 \\
\hline 3. Akım & $07: 00-10: 00$ & 6,89 & 7,6 & 0,91 & 9,70 & 1,41 & 1,28 \\
\hline 1. Akım & $10: 00-14: 00$ & 6,32 & 6,65 & 0,95 & 19,15 & 3,03 & 2,88 \\
\hline 2. Akım & $10: 00-14: 00$ & 6,27 & 6,72 & 0,93 & 13,93 & 2,22 & 2,07 \\
\hline 3. Akım & $10: 00-14: 00$ & 6,15 & 6,82 & 0,90 & 9,18 & 1,49 & 1,35 \\
\hline 1. Akım & $16: 00-20: 00$ & 7,52 & 7,58 & 0,99 & 125,33 & 16,67 & 16,53 \\
\hline 2. Akım & $16: 00-20: 00$ & 7,45 & 7,55 & 0,99 & 74,50 & 10,00 & 9,87 \\
\hline 3. Akım & $16: 00-20: 00$ & 7,03 & 7,42 & 0,95 & 18,03 & 2,56 & 2,43 \\
\hline
\end{tabular}

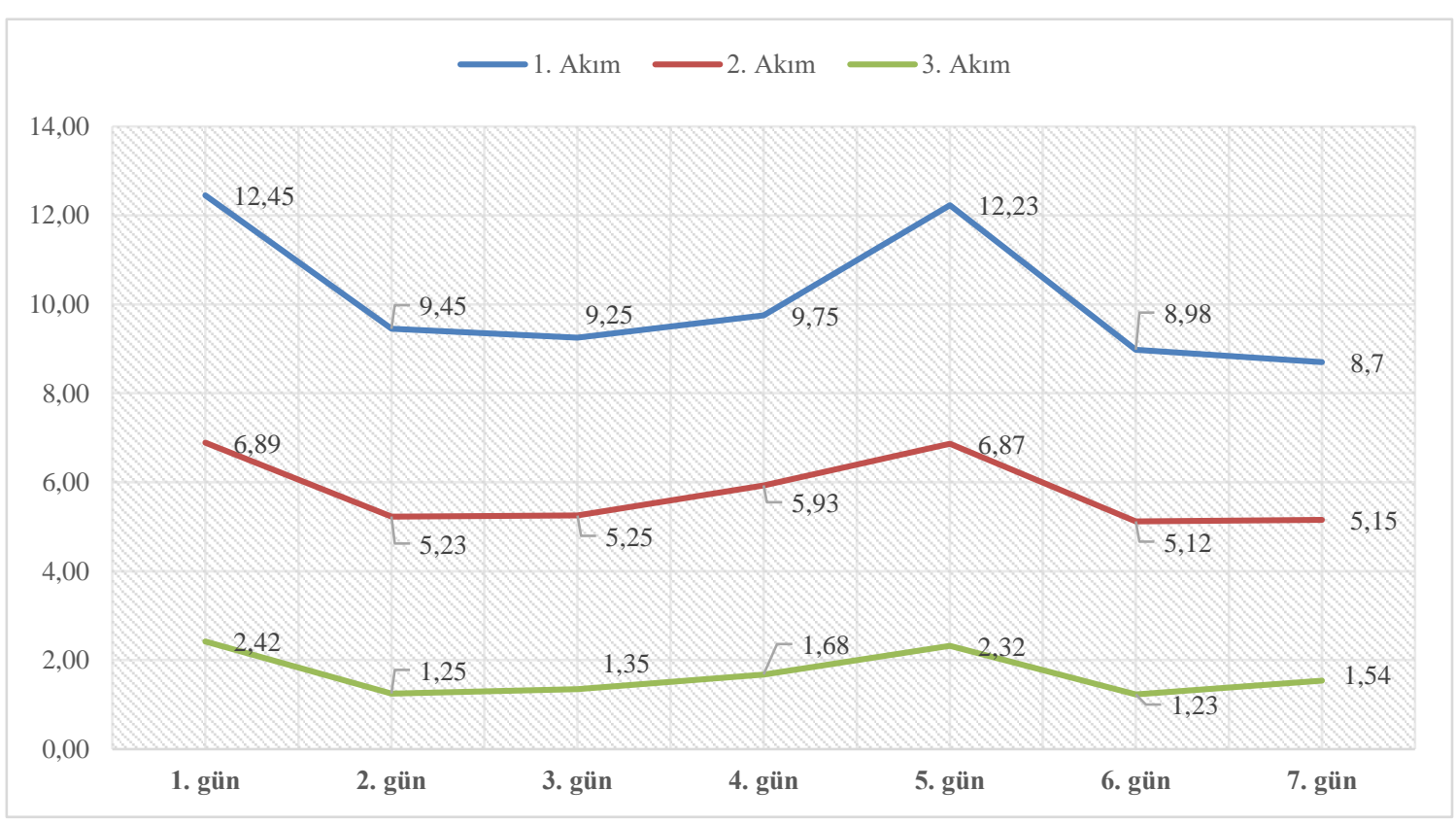

Şekil 4 Akımların günlere göre kuyruklarda yaşadı̆̆ı ortalama gecikmeler(saniye) 
Gerçek saha verileri üzerinden yapılan bu çalışmada örnek olarak alınan bir kavşağın günün üç yrı zaman diliminde verdiği sonuçlar ortaya çıkarılmıştır. M/M/1 modeli ile uyarlanan araştırmada kavşağın sahip olduğu üç trafik akımının yoğunluk ve araç bekleme gibi parametreleri Tablo 2'de görülmektedir. Şekil 4'te ise bir hafta boyunca her üç akımın ortalama yaşadığı beklemenin sonuçları (saniye) elde edilmiştir. Sonuçlar dikkatle incelendiğinde günün belli saat dilimlerinde akımlar arasında sürelerin düzgün dağılmadığ 1 ve yaklaşım kollarındaki yoğunlukların daha fazla dikkate alınması gerektiği ve kuyrukların buna göre boşaltılması gerektiği görülmektedir. Zira bir kolun kuyruk uzunluğu artarken fazla süre alarak o kolun boşaltılması yerine o anda çok fazla aracın olmadığı bir kol araç olmadan yeşil süre kullanabilmektedir. Örneğin Şekil 4'teki gecikmeler incelendiğinde 3. Akımı kullanan araçlar kuyruklanmadan kaynaklı ortalama 1,2 sn. zaman kaybederken 1. Akımdaki araçlar yaklaşı 9 sn. beklemektedir. Burada özellikle günün 7-10 ve 16-20 zaman periyotlarında 1 . Akım gibi öne çıkan yoğun kolların yeşil sürelerinin artırılması gerektiği sonucuna ulaşılmaktadır. Model ş̧ığında elde edilen veriler ile yapılan bu çalışma sonucunda ortaya çıkan kuyruk uzunluğu, ortalama araç beklemeleri veya bağlantı kollarının yoğunlukları gibi parametreler, kavşak modellemesi, sinyal veya faz planlaması gibi problemlerde önemli birer girdi olarak değerlendirilebilir.

\section{Sonuç}

Yapılan bu çalışmada literatürde özellikle üzerinde durulan ve birçok çalışmada referans olarak kabul edilen temel gecikme ve kapasite modelleri derlenmiştir. Bu konuda kuyruklanma problemleri araştırmalarında kullanılan kuyruk teorisi yaklaşımı incelenmiştir. Örnek olarak seçilen bir kavşaktaki akış gerçek saha verileri ile incelenerek kuyruk yaklaşımlarından M/M/1 ile modellenmiştir. Modelin sunmuş olduğu analitik yöntemler aracıllğıyla akım yoğunlukları, kuyrukta kaybedilen zaman, araç bazlı kuyruk uzunluğu, sistemde geçirilen zaman gibi bir kavşağın analizi için gerekli olabilecek performans ölçütleri elde edilmiştir. Yapılan incelemelerde araștırma sonuçları ve tartışma bölümü altında görüldüğ̈̈ üzere bazı kolların trafik ıșığı sürelerinin iyileştirilmesi gerekmektedir. Günün belli zaman dilimlerinde bazı akımların yoğun olduğu ve buna dikkat edilirse zaman, yakıt, enerji gibi tasarrufların elde edilebileceği belirtilebilir.

Kuyruk teorisi yaklaşımları bu türden trafik problemleri için analitik tabanlı çözümler sunmaktadır. Burada bu yaklaşımın farklı bileșenleri için daha farklı çalışmalar yapmak mümkündür. Örneğin özellikle varsayım olarak kabul edilen Poisson dağılım modeline uymayan geliş dağılımları ve servis süreleri gibi akımlar farklı dağılımlar ile modellenebilir. Örneğin gelişlerin veya gelişler arası sürelerin istatistiki dağılım modellerine göre akımın modellemesi $\mathrm{M} / \mathrm{G} / 1$ ya da $\mathrm{G} / \mathrm{G} / 1$ gibi modeller ile analiz edilmesi mümkündür. Ayrıca bazı akımlarda gerçek hayatta her zaman servis süreleri geliş oranlarını karşılayamayabilir ve buna bağlı olarak yoğunluğun oluştuğu kollara öncelik verisi atanarak yoğunluk öncelikli kavşak faz modelleri tasarlanabilir. Kararlı durum yani servis sürelerinin gelişleri karşılayamadığı durumlarda bu kollara belli bir doygunluk sınır değeri atanarak bu sınıra yaklaşan akım önceliklendirme ile boşaltılabilir.

\section{Teşekkür}

Bu araştırma İstanbul Büyükşehir Belediyesi kurumlarından İsbak A.Ş. tarafından veri olarak desteklenmiştir. Çalışmaya destek veren tüm İsbak A.Ş. yetkililerine teşekkür etmek ve en iyi dileklerimizi sunmak istiyoruz.

\section{Kaynakça}

Ağırdır, M.L. (1998). Kuyruk Teorisi Analizi ve Sinyalize Kavşaklarda Yeni Bir Model. Doktora Tezi, Karadeniz Teknik Üniversitesi, Fen Bilimleri Enstitüsü, 162s, Trabzon,

Akcelik, Rahmi. (1981). Traffic Signals: Capacity and Time Analysis, Australian Road Research Board, Research Report ARR No.123, Nunawading, Australia

Akcelik, R. (1980). Time -Dependent Expressions for Delay, Stop rate and Queue Length at Traffic Signals. Australian Road Research Board. Internal Report AIR, 367-1

Akcelik, R. (1988). The Highway Capacity Manual delay Formula for Signalized Intersections. ITE Journal Vol. 58(3), pp. $23-27$.

Akcelik, R. (1990), Appendix: A Note on the Generalised Delay Model. Compendium of Technical Papers, 60th Annual Meeting of Institute of Transportation Engineers, Orlando Florida, pp. 217-219.

Akgungor, A P, Bullen. (1999). Analytical Delay Models for Signalized Intersections, Transportation Frontiers for the Next Millennium: 69th Annual Meeting of the Institute of Transportation Engineers Location: Las Vegas

Armağan, K. (2019). The New Technological Advances in Highway Pavements: A Review. Avrupa Bilim ve Teknoloji Dergisi, (17), 1092-1096

Ayfer, M. Ö. (1977). Trafik sinyalizasyonu. Bayındırlık Bakanlığı, Karayolları Genel Müdürlüğü. Yayın No: 226, 46-67, Ankara.

B. Zhou, J. Cao, X. Zeng and H. Wu. (2010). Adaptive Traffic Light Control in Wireless Sensor Network-Based Intelligent Transportation System. IEEE 72nd Vehicular Technology Conference- Fall, Ottawa, ON, pp. 1-5, doi: 10.1109/VETECF.2010.5594435.

Buckley, D. J. (1962). Road traffic distributions. Proceedings of the Australian Road Research Board 1, 1533187.

Bullock, D. M., J. R. Sturdevant, and C. M. Day. (2008). Signalized Intersection Performance Measures for Operations DecisionMaking. ITE Journal, Vol. 78(8), pp. 20-23.

Cakici, Z., Murat. Y. S. (2015). Sinyalize Dönel Kavşakların Performanslarının Farklı Senaryolar Altında İncelenmesi, 11. Ulaştırma Kongresi, 27-29 Mayıs, İstanbul-Türkiye, 105-116. 
Cakici, Z., Murat, Y. S., Aydin, M. M. (2019). An Empirical Model for the Estimation of Fuel Consumption at Signalized Intersections. 3rd International Conference on Advanced Engineering Technologies, September 19-21, Bayburt-Turkey,1000-1010.

Caliskanelli S.P., Sinyalizasyon Sistemlerinden ayrılan Araçların Takip Aralı̆̆ı Dağılımının İncelenmesi, Doktora Tezi, Dokuz Eylül Üniversitesi Fen Bilimleri Enstitüsü, Aralık 2010

Francois Dion a, Hesham Rakha b, Youn-Soo Kang c. (2004). Comparison of delay estimates at under-saturated and over-saturated pretimed signalized intersections, Transportation Research Part B 38, 99-122.

Fambro, D., N. Rouphail P. Sloup, J. Daniel, and J. Li. (1996). Highway Capacity Manual Revisions of Chapters 9 and 11, Report No. FHWA-RD-96-088, 204pp.

Harb, A, Durdu, A, Terzioglu, H. (2019). Kavşak Trafik Sinyalizasyon Kontrolü için Bulanık Mantık Yöntemi ile Gerçek Zamanlı Sistemin Tasarımı ve Uygulamas1. Avrupa Bilim ve Teknoloji Dergisi, 490-497. DOI: 10.31590/ejosat.638612

Heidemann, D. (1991). Queue length and waiting time distributions at priority intersections. Transportation Research-B, 25, pp 163174.

Ilıcalı, M., Toprak, T., Özen, H., Tapkın, S., Öngel, A., Camkesen, N., Kantarcı, M. (2016). Akıcı-Güvenli Trafik için Akıllı Ulaşım Sistemleri, Erişim adresi: $\quad$ https://ww4.ticaret.edu.tr/ulastirma/wp-content/uploads/sites/85/2016/05/AKICIG\%c3\%9cVENL\%c4\%b0-TRAF\%c4\%b0K-\%c4\%b0\%c3\%87\%c4\%b0N-AKILLI-ULA\%c5\%9eIMS\%c4\%b0STEMLER\%c4\%b0.pdf

Kimber, R.M. and E.M. Hollis. (1979). Traffic Queues and Delays at Road Junctions. TRRL Laboratory Report 909, Berkshire, England.

Murat Y. S., Cakici Z., (2017). Sinyalize Kavşaklarda Durma Gecikmesi ve Kontrol Gecikmesi Arasındaki İlişkinin İncelenmesi, Ulaştırma Kongresi Bildiriler Kitabı, Volume: 12, At: 13-24

Özen, M. (2020). Kentsel Kavşaklarda Trafik Kazalarının Sıklı̆̆ını Etkileyen Faktörlerin İncelenmesi. Teknik Dergi, 31 (3). DOI: $10.18400 /$ tekderg. 509128

Transportation Research Board. (1985). Highway Capacity Manual, TRB Special Report 209, National Research Council, Washington D.C.

Traffic Signal Settings, by F.V. Webster. (1958). Road Research Technical paper No. 39, Ministry of Transport, Her Majesty's Stationary Office, 1958.

Transportation Research Board. (1994). Highway Capacity Manual 1994, TRB, NRC, Washington, DC.

Transportation Research Board. (1997). Highway Capacity Manual 1997, TRB, NRC, Washington, DC.

Transportation Research Board. (2000). Highway Capacity Manual 2000, TRB, NRC, Washington, DC.

Webster. (1958). F. V., Traffic Signal Settings, Road Research Technical Paper No. 39, Road Research Laboratory, Her Majesty's Stationery Office, Berkshire, England.

Yisheng Lv, Yanjie Duan, Wenwen Kang, Zhengxi Li, and Fei-Yue Wang. (2015). Traffic Flow Prediction With Big Data: A Deep Learning App, IEEE Transactions on Intelligent Transportation Systems, vol. 16(2) 